\title{
Morphological study of aluminum tris(8-hydroxyquinoline) thin films using infrared and Raman spectroscopy
}

\author{
R. J. Curry ${ }^{\mathrm{a})}$ \\ Optoelectronics Research Centre, University of Southampton, Southampton SO17 1BJ, United Kingdom \\ W. P. Gillin \\ Department of Physics, Queen Mary, University of London, London E1 4NS, United Kingdom \\ J. Clarkson and D. N. Batchelder \\ Department of Physics and Astronomy, University of Leeds, Leeds LS2 9JT, United Kingdom
}

(Received 14 November 2001; accepted for publication 30 May 2002)

\begin{abstract}
We present comprehensive Raman spectra for thin films of $\mathrm{Alq}_{3}$, annealed at various temperatures up to $300{ }^{\circ} \mathrm{C}$, over the range of $70-1800 \mathrm{~cm}^{-1}$. These spectra give strong evidence for structural rearrangement of thin films of $\mathrm{Alq}_{3}$ upon annealing at temperatures above $200{ }^{\circ} \mathrm{C}$. Needle like crystals are observed to grow in the films and confirmed to be comprised of the $\alpha$ - $\mathrm{Alq}_{3}$ polymorph using the low energy Raman spectra. Furthermore, no evidence of the fac isomer or thermal interconversion between the mer and fac isomers of $\mathrm{Alq}_{3}$ was observed in either the infrared or Raman spectra of the thin films or powder. These results may have implications for the long-term efficiencies of organic light emitting diodes incorporating thin films of $\mathrm{Alq}_{3}$. (C) 2002 American Institute of Physics. [DOI: 10.1063/1.1495527]
\end{abstract}

\section{INTRODUCTION}

Aluminum tris (8-hydroxyquinoline) $\left(\mathrm{Alq}_{3}\right)$ is one of the most widely used molecules in organic light emitting diodes (OLEDs) following the demonstration of an efficient device utilizing the molecule. ${ }^{1}$ In addition to earlier studies of $\mathrm{Alq}_{3},{ }^{2-6}$ this use of the molecule for OLED applications has lead to a number of more recent studies. ${ }^{7-20}$ Despite all this research the role of the morphology of $\mathrm{Alq}_{3}$ films on the performance and stability of OLEDs incorporating them is still not clear.

Two geometric isomers of $\mathrm{Alq}_{3}$ exist, mer $\left(\mathrm{C}_{1}\right.$ symmetry) and $f a c\left(\mathrm{C}_{3}\right.$ symmetry), and thermal interconversion between the two has previously been suggested. ${ }^{5}$ Evidence suggests that such interconversion is not a prerequisite for obtaining amorphous films. ${ }^{16}$ However, it has been suggested that the two isomers coexist in the amorphous state, which may result in an increase in the stability of this state. ${ }^{18}$ Additionally it is thought that the fac isomer, even as a minority isomer, may play an important role in devices as it is a more efficient electron trap than the mer isomer. ${ }^{14}$ Studies using density functional calculations and Hartree-Fock analysis of the isomers indicate that they can be identified using Raman and infrared (IR) spectroscopy ${ }^{13,17,20}$ although to date no spectral evidence of the $f a c$ isomer has been reported.

Detailed studies of the mer isomer have revealed that three different polymorphs of $\mathrm{Alq}_{3}$ can exist, labeled $\alpha-\mathrm{Alq}_{3}, \beta-\mathrm{Alq}_{3}$, and $\gamma-\mathrm{Alq}_{3} .{ }^{16}$ The first two of these polymorphs were identified using Raman spectroscopy.

To date the majority of IR spectra that have been reported were obtained from $\mathrm{Alq}_{3}$ powder dispersed in $\mathrm{KBr}^{13,16,20}$ or an argon matrix. ${ }^{17}$ One reflection-absorption

a) Author to whom correspondence should be addressed; electronic mail: ric@orc.soton.ac.uk
IR spectra has been published of a $200 \mathrm{~nm}$ film although no data below $700 \mathrm{~cm}^{-1}$ was presented. ${ }^{13}$ Published Raman spectra are all obtained from $\mathrm{Alq}_{3}$ in the solid state. ${ }^{13,16,20}$

In this work we give detailed IR and Raman spectra of $\mathrm{Alq}_{3}$ powder and thin films annealed at temperatures ranging from ambient to $300{ }^{\circ} \mathrm{C}$. The Raman spectra obtained cover the range $70-1800 \mathrm{~cm}^{-1}$ thus enabling the morphology of thin films to be studied and compared to previous work on solid $\mathrm{Alq}_{3}$. IR spectra of the thin films were also obtained from 270 to $2000 \mathrm{~cm}^{-1}$, although only the previously unpublished region below $670 \mathrm{~cm}^{-1}$ for thin films is presented. We then discuss the results and their implications for OLEDs based on thin layers of $\mathrm{Alq}_{3}$.

\section{EXPERIMENTAL METHOD}

The $\mathrm{Alq}_{3}$ powder was obtained from Aldrich and used without further purification. Films of $\mathrm{Alq}_{3}$ were sublimed under a vacuum of $\sim 10^{-6}$ mbar at a rate of $1-2 \AA / \mathrm{s}$ onto $\mathrm{WSi}_{2}$ and $\mathrm{KBr}$ substrates. The substrate temperature was not controlled and the resulting $\mathrm{Alq}_{3}$ film thicknesses were 635 $\mathrm{nm}$ on the $\mathrm{WSi}_{2}$ and $50 \mathrm{~nm}$ on the $\mathrm{KBr}$ substrates, measured using a calibrated quartz crystal thickness monitor.

Annealing of the films was carried out under a flowing nitrogen atmosphere using a barrel furnace. Each anneal was for $1 \mathrm{~h}$ at a temperature of 50,100,150, 200, 225, 250, or $300{ }^{\circ} \mathrm{C}$.

$\mathrm{KBr}$ disks incorporating $\mathrm{Alq}_{3}$ powder $(0.1 \%$ by weight $)$ were also prepared. The IR absorption spectra were obtained using a Perkin Elmer 2000 Fourier transform IR spectrometer with a resolution of $0.5 \mathrm{~cm}^{-1}$. The Stokes Raman spectra were obtained using a Renishaw Raman microscope with an excitation wavelength of $244 \mathrm{~nm}$. The anti-Stokes Raman spectra $\left(-500\right.$ to $\left.-70 \mathrm{~cm}^{-1}\right)$, observed due to photoluminescence obscuring the Stokes lines, were obtained using a Ren- 


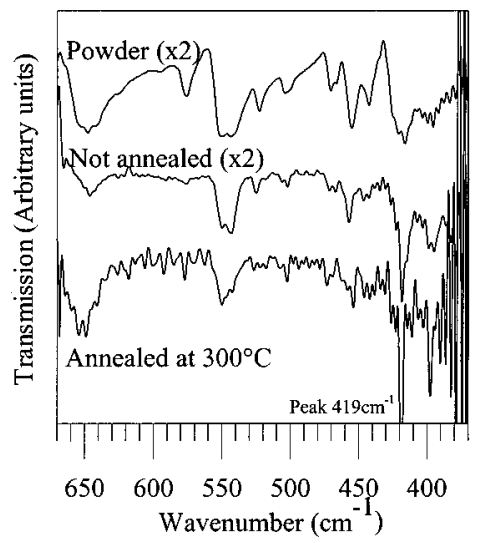

FIG. 1. The IR transmission spectra of $\mathrm{Alq}_{3}$ powder dispersed in a $\mathrm{KBr}$ disk, a $50 \mathrm{~nm}$ sublimed film of $\mathrm{Alq}_{3}$, and a $50 \mathrm{~nm}$ sublimed film of $\mathrm{Alq}_{3}$ following annealing at $300{ }^{\circ} \mathrm{C}$.

ishaw Raman microscope system fitted with a Leica DMCN microscope incorporating a charge coupled device (CCD) camera. The excitation source used was a $632 \mathrm{~nm} \mathrm{HeNe}$ laser and the system had a resolution of better than $1 \mathrm{~cm}^{-1}$. The images of the $\mathrm{Alq}_{3}$ sublimed films were obtained using the CCD camera on the microscope using a $\times 20$ objective. All Raman spectra were taken using a $\times 50$ objective.

\section{RESULTS AND DISCUSSION}

Figure 1 shows the IR spectra of $\mathrm{Alq}_{3}$ powder dispersed in a $\mathrm{KBr}$ disk and two sublimed films of $\mathrm{Alq}_{3}$ (on $\mathrm{KBr}$ substrates) one of which has been annealed at $300{ }^{\circ} \mathrm{C}$. Similarly, Fig. 2 shows the Raman spectra for $\mathrm{Alq}_{3}$ powder and sublimed films on $\mathrm{WSi}_{2}$ substrates obtained using the $244 \mathrm{~nm}$ excitation source. The IR spectrum of the powder clearly shows what appears to be two sets of doublet peaks at $\sim 550$ and $\sim 650 \mathrm{~cm}^{-1}$ and a single peak at $523 \mathrm{~cm}^{-1}$ that correspond to the Al-O stretching modes of the mer isomer of $\mathrm{Alq}_{3} \cdot{ }^{17,20}$ Figure 2 shows a similar set of doublets centered at $\sim 540$ and $640 \mathrm{~cm}^{-1}$. Simulated Raman and IR spectra both indicate that the $f a c$ isomer exhibits only a single peak at these positions. ${ }^{13,17}$ Therefore the observation of doublets at these positions is strong evidence that the mer isomer is the predominant species in both the powder and the sublimed film reported here. The annealing at $300{ }^{\circ} \mathrm{C}$ of the $\mathrm{Alq}_{3}$ film has little effect on the position of these peaks in the IR and Raman spectra but does appear to increase the resolution of the doublet structures. Interestingly the peaks centered at $\sim 550 \mathrm{~cm}^{-1}$ in the IR spectrum appear to be comprised of at least three peaks centered at 542,548 , and $550 \mathrm{~cm}^{-1}$. The emergence of a third peak is not evidence of any thermal interconversion between the mer and fac isomer but may be the result of a change in the packing of the $\mathrm{Alq}_{3}$ following annealing as will be discussed later.

The other noticeable effect of annealing is to significantly increase the strength of the IR absorption peaks observed at 418 and $398 \mathrm{~cm}^{-1}$, thus helping to resolve the multiplets centered on these peaks. These absorptions have been associated with $\mathrm{O}-\mathrm{Al}$ stretching and $\mathrm{C}-\mathrm{O}-\mathrm{Al}$ bending



FIG. 2. The Raman spectra of $\mathrm{Alq}_{3}$ powder, a $635 \mathrm{~nm}$ sublimed film of $\mathrm{Alq}_{3}$, and a $635 \mathrm{~nm}$ sublimed film of $\mathrm{Alq}_{3}$ following annealing at $300{ }^{\circ} \mathrm{C}$.

modes. It might be expected that an increase in the packing order would have the effect of enhancing some of these modes while reducing others.

Brinkmann et al. showed that there exists at least three phases of $m e r \mathrm{Alq}_{3}$ and showed that the $\alpha$ and $\beta$ phase could be distinguished using low energy Raman spectra. ${ }^{16}$ Figure 3 shows such a Raman spectra of $\mathrm{Alq}_{3}$ powder, a sublimed film of $\mathrm{Alq}_{3}$ (on a $\mathrm{WSi}_{2}$ substrate), and various areas of sublimed films annealed at 225 and $300{ }^{\circ} \mathrm{C}$ over the range -500 to $-70 \mathrm{~cm}^{-1}$. Figure 4 shows microscope images of the regions of the sublimed films that the spectra shown in Fig. 3 were obtained. The Raman spectrum of the $\mathrm{Alq}_{3}$ powder shows a main broad peak centered at $109 \mathrm{~cm}^{-1}$ with a shoulder at $\sim 95 \mathrm{~cm}^{-1}$. Within this broad peak lie two of the Raman "fingerprints" used to identify the $\alpha$ - $\mathrm{Alq}_{3}$ and $\beta$ - $\mathrm{Alq}_{3}$, at 117 and $109 \mathrm{~cm}^{-1}$, respectively. ${ }^{16}$ The origin of this broad peak is still somewhat unclear. Calculations of the vibrational modes for both the mer and fac isomers do not predict any modes between $\sim 135$ and $55 \mathrm{~cm}^{-1} \cdot{ }^{13,17,20}$ However, the frequency of such low energy modes is highly dependent on the molecular arrangement (hence the ability to distinguish between the two polymorphs). Currently it is thought that this broad peak originates from vibrations of the central $\mathrm{Al}$ ion mainly involving the torsional $\mathrm{O}-\mathrm{Al}$ and $\mathrm{N}-\mathrm{Al}$ modes. ${ }^{20}$

In addition to the main peak two other peaks are visible at 155 and $165 \mathrm{~cm}^{-1}$. The former of these peaks coincides with the second Raman fingerprint of $\alpha-\mathrm{Alq}_{3}$ and both result from modes involving the $\mathrm{O}-\mathrm{Al}-\mathrm{N}$ bonds, the "butterfly" modes of the ligands. ${ }^{17,20}$ The position of the main peak, the peak at $152 \mathrm{~cm}^{-1}$, along with the lack of any peak at 183 $\mathrm{cm}^{-1}$ suggests that the powder is comprised of mainly the $\alpha-\mathrm{Alq}_{3}$ polymorph.

If we compare the Raman spectra of the $\mathrm{Alq}_{3}$ powder and sublimed film that has not been annealed, shown in Fig. 4(a), there are some obvious differences. First the main broad peak has moved from 108 to $95 \mathrm{~cm}^{-1}$ upon sublimation of the $\mathrm{Alq}_{3}$. Additionally the peak at $152 \mathrm{~cm}^{-1}$ has reduced in intensity while a peak at $194 \mathrm{~cm}^{-1}$, related to a torsional $\mathrm{N}-\mathrm{Al}$ mode, has emerged. Also apparent is a broad- 


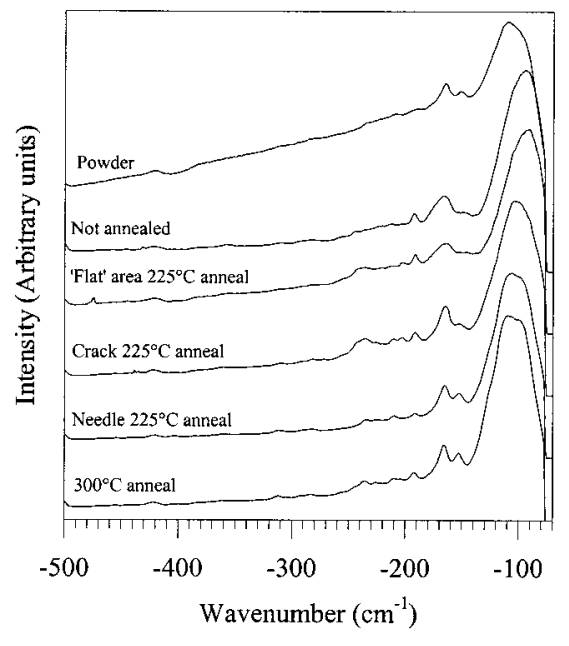

FIG. 3. The $632 \mathrm{~nm}$ excited Raman spectra of $\mathrm{Alq}_{3}$ powder, a $635 \mathrm{~nm} \mathrm{Alq}$ film as deposited, three areas of a $635 \mathrm{~nm} \mathrm{Alq}_{3}$ film annealed at $225^{\circ} \mathrm{C}$ for $1 \mathrm{~h}$, and a $635 \mathrm{~nm} \mathrm{Alq}{ }_{3}$ film annealed at $300{ }^{\circ} \mathrm{C}$ for $1 \mathrm{~h}$.

ening of the peak at $165 \mathrm{~cm}^{-1}$ with close inspection revealing a peak centered at $\sim 176 \mathrm{~cm}^{-1}$. The reduction in the presence of the $\alpha-\mathrm{Alq}_{3}$ fingerprints along with no evidence of the $\beta-\mathrm{Alq}_{3}$ polymorph is consistent with the deposited film being amorphous. There is a possibility that the sublimed film may be comprised of the disordered $\gamma-\mathrm{Alq}_{3}$ polymorph. However, given that the $\alpha$ - $\mathrm{Alq}_{3}$ to $\gamma$ - $\mathrm{Alq}_{3}$ conversion occurs above $395{ }^{\circ} \mathrm{C},{ }^{17}$ which is above the sublimation temperature used, we feel that this is unlikely. As has been previously noted for the reflection-absorption IR spectra of $200 \mathrm{~nm} \mathrm{Alq}{ }_{3}$ films ${ }^{13}$ we observed no change in the IR or Raman spectra upon annealing of the sublimed films at temperatures up to $200{ }^{\circ} \mathrm{C}$. At temperatures above this, however, the films are seen to start crystallizing as expected from thermal analysis of $\mathrm{Alq}_{3} .{ }^{9}$ The Raman spectra of three areas of a film annealed at $225^{\circ} \mathrm{C}$, Fig. 4(b), are shown in Fig. 3. The Raman spectrum of the featureless area of the film, labeled "flat" area, is similar to that of the unannealed film. However, changes can be seen in the spectra obtained from a crack in the film and a small needle like crystal (similar to that described by Brinkmann et al. ${ }^{16}$ ). In both of these spectra the main peak has moved back from $95 \mathrm{~cm}^{-1}$ toward the position observed in the spectrum obtained from the $\mathrm{Alq}_{3}$ powder. Furthermore, the peak at $152 \mathrm{~cm}^{-1}$ has re-emerged. Finally, Fig. 3 shows the Raman spectrum of the film annealed at $300{ }^{\circ} \mathrm{C}$, shown in Fig. 4(d). This film is almost entirely comprised of many needle like crystals. The Raman spectrum shows the characteristic $\alpha$ - $\mathrm{Alq}_{3}$ fingerprint at 154 $\mathrm{cm}^{-1}$ and a shoulder in the main peak at $\sim 120 \mathrm{~cm}^{-1}$ indicates the presence of the second fingerprint of this polymorph. The main peak can be seen to consist of two further peaks centered at 109 and $100 \mathrm{~cm}^{-1}$. The peak at $109 \mathrm{~cm}^{-1}$ may suggest that there is some of the $\beta$ - $\mathrm{Alq}_{3}$ polymorph present although no corresponding peak is observed at 183 $\mathrm{cm}^{-1}$. Additionally, peaks can be seen in the high-energy tail at $\sim 422,311,283$, and $235 \mathrm{~cm}^{-1}$ as previously described for $\mathrm{Alq}_{3} .{ }^{20}$

No Raman signals could be obtained for the $50 \mathrm{~nm}$ thick films on $\mathrm{KBr}$ substrates in the region below $400 \mathrm{~cm}^{-1}$. How-

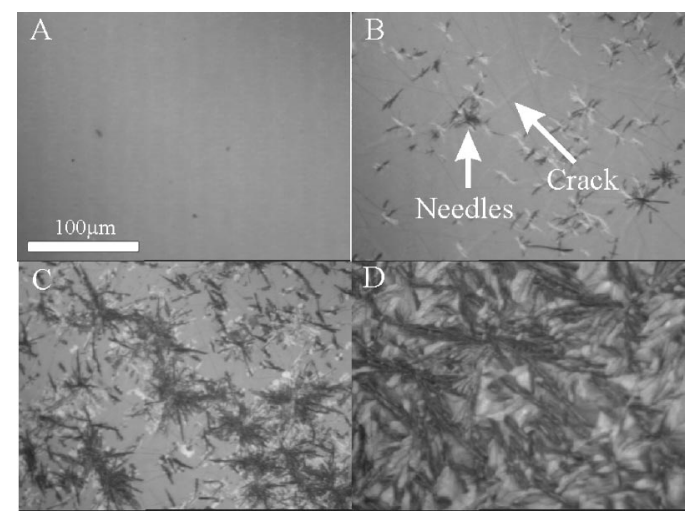

FIG. 4. Optical microscope images of: (a) an as deposited $635 \mathrm{~nm} \mathrm{Alq}$ film, (b) a $635 \mathrm{~nm} \mathrm{Alq}$ film annealed at $225^{\circ} \mathrm{C}$ for $1 \mathrm{~h}$, (c) a $635 \mathrm{~nm} \mathrm{Alq}$ film annealed at $250{ }^{\circ} \mathrm{C}$ for $1 \mathrm{~h}$, and (d) a $635 \mathrm{~nm} \mathrm{Alq}$ film annealed at $300{ }^{\circ} \mathrm{C}$ for $1 \mathrm{~h}$. Each image was taken using a $\times 20$ objective.

ever, the surface of the films did appear to change when viewed under a microscope after annealing at $300{ }^{\circ} \mathrm{C}$. This along with the changes observed for the thicker $635 \mathrm{~nm}$ films upon annealing suggest that some structural rearrangement has occurred in these films. Such an effect could explain the subtle changes observed in the IR spectra in Fig. 1. The possibility that these changes are due to volatile impurities incorporated into the films during sublimation being driven off cannot be ruled out. However, although the $\mathrm{Alq}_{3}$ was used as received, earlier "sacrificial" sublimations prior to the deposition of the films reported here would have significantly reduced this risk.

The results presented here have implications for OLED devices incorporating $\mathrm{Alq}_{3}$. No evidence of the fac isomer or thermal interconversion between the mer and fac isomers was found. The inability to observe the fac isomer makes any future analysis of the importance of the isomer in trapping electrons difficult. Indeed the isomer may not be present even as a minority within the films.

The change in morphology with annealing may have implications for devices with long operational lifetimes. Such a rearrangement of the film over a long time span may introduce nonradiative trap sites that will reduce the device efficiency. This rearrangement would tend to proceed quicker in device "hot spots" (e.g., areas of high current density), which then could act as "seeds" for more structural change thus reducing the efficiency further.

\section{CONCLUSIONS}

In conclusion we have presented comprehensive Raman spectra for thin films of $\mathrm{Alq}_{3}$ annealed at various temperatures between ambient and $300{ }^{\circ} \mathrm{C}$. These spectra give strong evidence for a structural rearrangement of the molecular packing within thin films of $\mathrm{Alq}_{3}$ upon annealing at temperatures above $200{ }^{\circ} \mathrm{C}$. Needle like crystals are observed to grow in the films and confirmed to be comprised of the $\alpha-\mathrm{Alq}_{3}$ polymorph using the low energy Raman spectra. Furthermore, no evidence of the fac isomer or thermal interconversion between the mer and fac isomers was observed in 
either the IR or Raman spectra of the thin films or powder. These results may have implications for the long-term efficiencies of OLEDs incorporating thin films of $\mathrm{Alq}_{3}$.

${ }^{1}$ C. W. Tang and S. A. VanSlyke, Appl. Phys. Lett. 51, 913 (1987).

${ }^{2}$ K. G. Stone, J. Am. Chem. Soc. 76, 4997 (1954).

${ }^{3}$ R. G. Charles, H. Freiser, R. Friedel, L. E. Hilliard, and W. D. Johnston, Spectrochim. Acta 8, 1 (1956).

${ }^{4}$ R. Larsson and O. Eskilsson, Acta Chem. Scand. 22, 1067 (1968).

${ }^{5}$ B. C. Baker and D. T. Sawyer, Anal. Chem. 40, 1945 (1968).

${ }^{6}$ P. J. Milham, A. W. Hudson, M. J. Maguire, K. S. Haddad, and C. C. Short, Appl. Spectrosc. 33, 298 (1979).

${ }^{7}$ I. Fujii, N. Hirayama, J. Ohtani, and K. Kodama, Anal. Sci. 12, 153 (1996).

${ }^{8}$ K. Sano, Y. Kawata, T. I. Urano, and Y. Mori, J. Mater. Chem. 2, 767 (1992).

${ }^{9}$ K. Naito and A. Miura, J. Phys. Chem. 97, 6240 (1993).
${ }^{10}$ I. Fujii, N. Hirayama, J. Ohtani, and K. Kodama, Anal. Sci. 12, 153 (1996).

${ }^{11}$ E. Han, L. Do, N. Yamamoto, and M. Fujihira, Thin Solid Films 273, 202 (1996).

${ }^{12}$ J. D. Anderson et al., J. Am. Chem. Soc. 120, 9646 (1998).

${ }^{13}$ M. D. Halls and R. Aroca, Can. J. Chem. 76, 1730 (1998).

${ }^{14}$ A. Curioni, M. Boero, and W. Andreoni, Chem. Phys. Lett. 294, 263 (1998).

${ }^{15}$ R. J. Curry and W. P. Gillin, J. Appl. Phys. 88, 781 (2000).

${ }^{16}$ M. Brinkmann, G. Gadret, M. Muccini, C. Taliani, N. Masciocchi, and A. Sironi, J. Am. Chem. Soc. 122, 5147 (2000).

${ }^{17}$ G. P. Kushto, Y. Iizumi, J. Kido, and Z. H. Kafafi, J. Phys. Chem. A 104, 3670 (2000).

${ }^{18}$ A. Curioni and W. Andreoni, IBM J. Res. Dev. 45, 101 (2001).

${ }^{19}$ H. Ichikawa, T. Shimada, and A. Koma, Jpn. J. Appl. Phys., Part 2 40, L225 (2001).

${ }^{20}$ A. D. Esposti, M. Brinkmann, and G. Ruani, J. Chem. Phys. 116, 798 (2002). 